\title{
Pulmonary embolisation of retained transvenous pacemaker electrode
}

\author{
WOLFRAM THEISS AND ALEXANDER WIRTZFELD \\ From the I. Medizinische Klinik und Poliklinik, Klinikum Rechts der Isar der Technischen Universität, \\ D-8000 München 80, Germany
}

When removal of an endocardial pacemaker electrode became necessary in a patient with congestive myocardiopathy, it proved to be incarcerated. Therefore, a portion of it had to be left in site after cutting the external end of the pacing catheter. During follow-up examinations the electrode was seen to migrate in the large veins and finally was found embolized into a pulmonary artery. While there have been publications on the migration of retained pacemaker electrodes before, to our knowledge this represents the first case reported with pulmonary embolization of the migrating fragment.

Migration of a retained pacemaker electrode is an extremely rare event which has been reported only four times (Ramo et al., 1968; Tallury et al., 1972; Das et al., 1974; Soni, Lupi, and Mispireta, 1974). The following case differs from those described previously in that the migrating electrode left the venous system and was embolized into a major pulmonary artery. While pulmonary emboli originating from thrombi surrounding a transvenous pacemaker electrode do occasionally occur (Prozan et al., 1968; Marx et al., 1972), the patient described in this paper represents, to our knowledge, the first case of pulmonary embolization of the electrode itself.

\section{Case report}

The patient suffering from familial congestive myocardiopathy was first seen at our hospital in 1961 when he was 27 years old. During the following years he had to be admitted to hospital repeatedly for congestive heart failure. On all these occasions his electrocardiogram revealed atrial fibrillation with a slow ventricular response, and over the years there was a tendency to a progressive decrease in ventricular rate which had dropped to 30 beats/min by July 1973 . It was then decided to implant a permanent R-wave-inhibited demand pacemaker and the procedure was performed on 13 July 1973, using a unipolar pervenous electrode (Elema EMT $588 \mathrm{~A}$ ) introduced via the right internal jugular vein.
Subsequently several complications were encountered. An infection with Staphylococcus aureus developed at the implantation site necessitating removal of the pulse generator three weeks after its implantation. Another three weeks later a new pacer was implanted subcutaneously at the left pectoral area and was connected to the original electrode which had been left in place. Since signs of infection were noted over this implantation site as well, and as it was felt that the obviously persisting infection could only be eradicated by explanting the entire pacing system, it was decided to remove the pulse generator and the electrode on 6 February 1974. During the operation the electrode could not be pulled back any further beyond the right innominate vein. Therefore, it was cut near the point of its entrance into the jugular vein, and after the proximal portion had been removed, the distal portion was anchored with several transfixation sutures to the platysma. During the following months, while the patient's rate was controlled by medical treatment alone, a fistula developed at the original operation site over the internal jugular vein which was excised on 27 December 1974. While searching for the electrode tip on this occasion the internal jugular vein was lacerated and because of severe bleeding no further attempt was made to locate and remove the electrode tip.

The patient was next seen on 21 January 1975, after an epileptic seizure secondary to a cerebral embolus. At that time the pacemaker electrode tip was still visible on a chest $x$-ray film at its original 

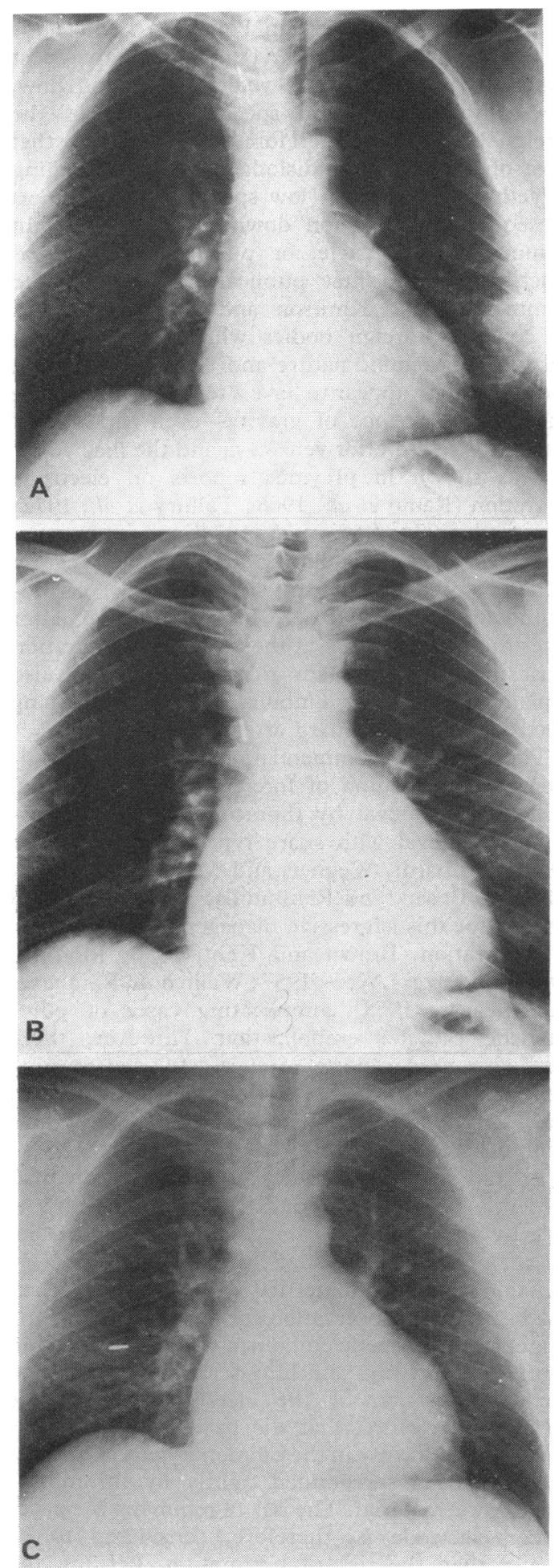
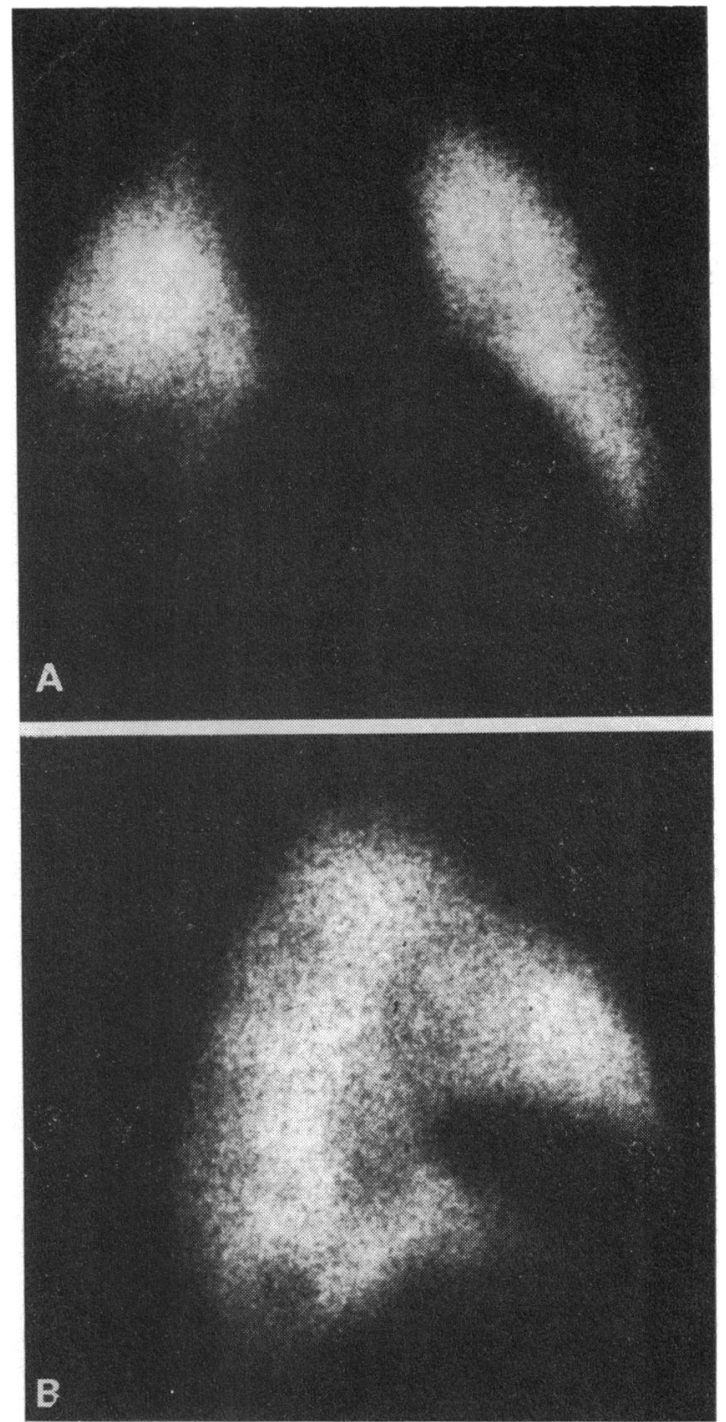

FIG. 2 Lung scan revealing lack of perfusion of the entire middle lobe of the right lung. ( $A)$ anteroposterior vicw; (B) right view.

FIG. 1 Chest $x$-ray films showing the location of the $\leftarrow$ severed proximal end of the pacemaker electrode: (A) 21 fanuary 1975: right innominate vein; (B) 24 April 1975: superior vena cava; (C) 4 September 1975 : pulmonary artery of the right middle lobe. 
position in the right innominate vein (Fig. 1A). On the next $x$-ray film during a routine visit on 24 April 1975, the tip of the electrode was located further down in the area of the superior vena cava (Fig. 1B), and when the patient was seen again on 4 September 1975, the electrode was found in the right middle lobe of the lung (Fig. 1C), and under fluoroscopy appeared to be lodged in the pulmonary artery of the right middle lobe. This was confirmed by lung scan which revealed lack of perfusion of the entire middle lobe of the right lung (Fig. 2). Physical examination of the lung, blood gas analysis, and pulmonary function tests were all within normal limits and no significant changes were found in the electrocardiogram as compared with that registered in April 1975. Careful questioning of the patient indicated no history suggestive of pulmonary embolisation or febrile disease during the months between April and September 1975.

\section{Discussion}

Electrode displacement and skin erosion with secondary infection are the complications which most commonly require replacement of an endocardial pacing electrode (Schmück et al., 1974). In cases of electrode displacement it is considered safe to leave the old electrode in place if it cannot easily be removed. In contrast, it is considered mandatory to remove pacing wires in cases of infection in order to control local and systemic septic complications (Imparato and Kim, 1972a). Special techniques have been described for the removal of these electrodes in cases where simple retraction proves impossible, because the electrode has become 'trapped' in the endocardium of the right ventricle (Imparato and $\mathrm{Kim}, 1972 \mathrm{~b}$ ). In other instances, the pacing electrode can successfully be dislodged from the right ventricle, but cannot be removed entirely from the venous system because fibrous bandssurrounding the pacing wire at portions where it had become attached to the ventricular musculature and the venous pathway-hinder its complete removal.

Suturing the stump of such electrodes to the surrounding tissues does not always successfully prevent secondary displacement as was observed on four occasions by different authors who reported migration of a retained endocardial pacemaker electrode (Ramo et al., 1968; Tallury et al., 1972; Das et al., 1974; Soni et al., 1974). In all of these 4 cases the pacing electrodes remained in the large veins and eventually drifted to the inferior vena cava and the iliac veins, from where they could be removed either with snare type catheters inserted via the saphenous vein or by laparotomy.
The migration of foreign bodies in the venous system is influenced by several factors, the most important ones being the velocity of blood flow, the body position, and specific gravity of the foreign body. It is, therefore, not surprising that most of the papers on dislodgement of indwelling polyethylene catheters (low specific gravity) report subsequent embolization 'down-stream' to the right atrium, right ventricle, or pulmonary artery, as described in the first publications (Turner and Sommers, 1954; Knutson and Stenberg, 1959). In contrast, foreign bodies which are totally or partially of metallic nature and hence have a high specific gravity appear to have a tendency to migrate under the influence of gravity-even 'up-stream' - towards the inferior vena cava and the iliac veins, as was shown in previous reports on electrode migration (Ramo et al., 1968; Tallury et al., 1972; Das et al., 1974; Soni et al., 1974) and on the displacement of the metallic tip of a coronary suction catheter during cardiac surgery with cardiopulmonary bypass (Irmer, 1964). In these latter cases the body position at the moment of migration must play the dominant role and this may also explain the peculiar embolization of the pacing electrode to a pulmonary artery in our patient.

Therapeutic recommendations concerning pulmonary embolization of foreign bodies in general include its removal by thoracotomy or by transvenous retrieval with snare type catheters (Irmer 1964; Bernhardt, Wegner, and Mendenhall, 1970; Dhingra, Rosen, and Rahimtolla, 1973). The main reasons for this aggressive management are reports of perforation (Brown and Kent, 1956; Johnson, 1966) and sepsis (Ayers, 1957; Wellmann, Reinhard, and Salazar, 1968) complicating cases of polyethylene catheter embolization. However, there have also been reports of successful conservative treatment of such cases (Borgeskov, Lauridsen, and Rygg, 1966; Bloos, Flörkemeier, and Schmücker, 1972).

In our case the event of embolization had evidently occurred without any symptoms noticeable by the patient. By the time it was diagnosed, no major disturbances of cardiac or pulmonary function could be discerned. By now the patient has been under observation for 5 months since the diagnosis of electrode embolism was first made, and control chest $x$-rays and lung scans have shown no further migration of the electrode. It can be assumed, therefore, that the pacing electrode has been wedged firmly in the pulmonary artery and has probably been surrounded tightly by thrombotic and fibrotic material. The risk of removing the pacemaker electrode is, therefore, considered to be greater than the risk of perforation. Besides, the 
possibility of sepsis originating from the electrode can be assumed to be very small in view of the previous good tolerance of the foreign body, which by now has been in the blood stream untouched for more than 15 months from the last operative procedure involving the implantation site.

We would like to thank Prof. Dr. H. Anacker (Institut für Röntgendiagnostik) for the $x$-ray films, and Prof. Dr. H. W. Pabst (Nuklearmedizinische Klinik and Poliklinik) for the lung scans.

\section{References}

Ayers, W. B. (1957). Fatal intracardiac embolization from indwelling intravenous polyethylene catheter. Archives of Surgery, 75, 259.

Bernhardt, L. C., Wegner, G. P., and Mendenhall, J. T. (1970). Intravenous catheter embolization to the pulmonary artery. Chest, 57, 329.

Bloos, I., Flörkemeier, V., and Schmücker, K. (1972). Venenkatheterembolie. Medizinische Welt, 23, 261.

Borgeskov, S., Lauridsen, P., and Rygg, J. H. (1966). Iatrogene fremmedlegemer $\mathrm{i}$ cor og de store kar. Nordisk Medicin, 76, 282.

Brown, C. A., and Kent, A. (1956). Perforation of right ventricle by polyethylene catheter. Southern Medical Fournal, 49, 466.

Das, P. B., McArthur, J. D., Gupta, R. P., Jairaj, P. S., and John, S. (1974). Migration of retained endocardial pacemaker electrode and its management. Indian Heart Fournal, 26, 198.

Dhingra, R. C., Rosen, K. M., and Rahimtoola, S. H. (1973). Transvenous removal of catheter fragments from the heart and pulmonary artery. Archives of Internal Medicine, $132,419$.

Imparato, A. M., and Kim, G. E. (1972a). Electrode complications in patients with permanent cardiac pacemakers. Archives of Surgery, 105, 705.

Imparato, A. M., and Kim, G. E. (1972b). The trapped endocardial electrode. Removal by prolonged graded skin traction. Annals of Thoracic Surgery, 14, 605.
Irmer, W. (1964). Entfernung eines embolisch von der linken Kubitalvene eingeschwemmten Polyäthylen-Katheters aus dem Pulmonalisstamm. Zentralblatt für Chirurgie, 89, 1078.

Johnson, C. E. (1966). Perforation of right atrium by a polyethylene catheter. Fournal of the American Medical Association, 195, 584.

Knutson, H., and Stenberg, K. (1959). Lungenemboli efter kateterbrott. Nordisk Medicin, 62, 1491.

Marx, E., Schulte, H. D., Balau, J., and Buysch, K. A. (1972). Phlebographische und klinische Früh- und Spätbefunde bei transvenös implantierten Schrittmacherelektroden. Zeitschrift für Kardiologie, 61, 115.

Prozan, G. B., Shipley, R. E., Madding, G. F., and Kennedy, P. A. (1968). Pulmonary thromboembolism and pacing catheter. Fournal of the American Medical Association, 206, 1564.

Ramo, B. W., Peter, R. H., Kong, Y., and Morris, J. J., Jr. (1968). Migration of a severed transvenous pacing catheter and its successful removal. American fournal of Cardiology, 22, 880.

Schmück, L., Präuer, W., Hilber, C., and Rutner, H. (1974). Korrektureingriffe nach Implantation permanenter Herzschrittmacher. Medizinische Klinik, 69, 988.

Soni, C. J., Lupi, H. E., and Mispireta, J. (1974). Retención, anclaje y migración de electrodo endovenoso de marcapaso permanente. Su extraccion con catéter de Dormia. Comunicación de un caso. Archivos del Instituto de Cardiologia de Mexico, 44, 782.

Tallury, V. K., dePasquale, N. P., Bruno, M. S., and Nody, A. C. (1972). Migration of retained transvenous electrode catheter. Archives of Internal Medicine, 130, 390.

Turner, D. D., and Sommers, S. C. (1954). Accidental passage of a polyethylene catheter from cubital vein to right atrium. New England fournal of Medicine, 251, 744.

Wellmann, K. F., Reinhard, A., and Salazar, E. P. (1968). Polyethylene catheter embolism: review of the literature and report of a case with associated fatal tricuspid and systemic candidiasis. Circulation, 37, 380.

Requests for reprints to Dr. Wolfram Theiss, I. Med. Klinik und Poliklinik, Rechts der Isar, D-8000 München 80, Ismaningerstr. 22, WGermany. 